\title{
Preparation and Self-Repairing Properties of Urea Formaldehyde- Coated Epoxy Resin Microcapsules
}

\author{
Xiaoxing Yan $\mathbb{D}^{1,2}$ Yijuan Chang, ${ }^{2}$ and Xingyu Qian ${ }^{2}$ \\ ${ }^{1}$ Co-Innovation Center of Efficient Processing and Utilization of Forest Resources, Nanjing Forestry University, \\ Nanjing 210037, China \\ ${ }^{2}$ College of Furnishings and Industrial Design, Nanjing Forestry University, Nanjing 210037, China
}

Correspondence should be addressed to Xiaoxing Yan; xxyan255@126.com

Received 17 April 2019; Accepted 31 August 2019; Published 18 September 2019

Academic Editor: De-Yi Wang

Copyright (C) 2019 Xiaoxing Yan et al. This is an open access article distributed under the Creative Commons Attribution License, which permits unrestricted use, distribution, and reproduction in any medium, provided the original work is properly cited.

Urea formaldehyde resin-coated epoxy resin microcapsules were prepared by two-step in situ polymerization. The effects of five factors on the yield, coverage rate, repair rate, and morphology of the microcapsules were investigated by five factors and four levels of orthogonal test. These five factors were the mass ratio of the core to the wall material $\left(W_{\text {core }}: W_{\text {wall }}\right)$, the mass ratio of the emulsifier to the core material $\left(W_{\text {emulsifier }}: W_{\text {core }}\right)$, stirring rate, deposition time, and mass ratio of the emulsifier solution to the core material $\left(W_{\text {emulsifier solution }}: W_{\text {core }}\right)$. The ideal technological level of microcapsule synthesis was determined. According to the results of the range and variance of yield, coverage rate, and repair rate, the comprehensive properties of microcapsules became ideal. At this time, the $W_{\text {core }}: W_{\text {wall }}$ was $0.8: 1, W_{\text {emulsifier }}: W_{\text {core }}$ was $1: 100$, stirring rate was $600 \mathrm{r} / \mathrm{min}$, deposition time was $32 \mathrm{~h}$, and $W_{\text {emulsifier solution }}: W_{\text {core }}$ was $8: 1$. When the concentration of microcapsules in the epoxy resin was $10.0 \%$, the self-repair rate was the best and the repair rate was $114.77 \%$. This study is expected to provide a reference value for the preparation of a microcapsule self-healing technology and lay a foundation for the subsequent development of selfhealing materials.

\section{Introduction}

A finishing process is an important means to adjust surface characteristics, but its process is complex, and it is easy to produce many fine defects in the process of finishing and subsequent production. In recent years, by imitating the self-repair function of the organism and the participation of external environmental factors, internal and external damage can be automatically repaired in the matrix material and the useful life of the material can be prolonged [1]. Bolimowski et al. prepared microcapsules from commercially available epoxy resin and an organic solvent (ethyl phenylacetate (EPA)) for application to self-healing epoxides [2]. The application of the self-repair technology of the microcapsule to a coating surface can avoid a complicated artificial repair when the coating surface is damaged and cracked, and thus, the life of the coating can be improved and the useful period is prolonged [3]. A microencapsulation self-repairing technology has very broad application prospects in wood coat- ings [4], pigments, textile printing, and dyeing, as well as architectural, aerospace, and ship coatings [5]. Through the microencapsulation technology, the anticorrosion, antifouling, heat insulation, and flame retardant functions of coatings were enhanced according to requirements and the application scope of the coating was broadened.

In the preparation of self-repair microcapsules, the selection of core and wall materials for a microcapsule system is particularly important. A microencapsulated self-repairing system mainly includes the dicyclopentadiene-Grubbs curing agent system, epoxy resin core microcapsule self-repairing system, isocyanate microcapsule self-repairing system, dry oil microcapsule self-repairing system, polar solvent core self-repairing system, siloxane self-repairing system, and silicone oil self-repairing system. However, it is still difficult for these self-repairing systems to be widely used in the field of coatings. Based on research results, the microcapsule preparation method selected was in situ polymerization, which is easy to control and easily realized [6]. Microcapsules 
of the epoxy resin system have high hardness, good flexibility, good adhesion to metal and nonmetal, and good dimensional stability and are widely used in paint, adhesions, impregnation, and so on, which is very suitable for self-repair of coatings [7]. However, the morphology of epoxy resin microcapsules is not easy to control and the coverage rate and repair rate are relatively low, which is not conducive for industrial production and application. Therefore, in this paper, the microcapsule of urea formaldehyde-coated epoxy resin (epoxy resin coated with urea formaldehyde) was selected as the research object. In situ polymerization was used to prepare the microcapsules, and the best technological parameters for the preparation of the self-repair microcapsule of the coatings were explored in order to establish a foundation for the application of the self-healing microcapsules in engineering.

\section{Experimental}

2.1. Materials. Urea $\left(M_{w}: 60.06 \mathrm{~g} / \mathrm{mol}\right.$, CAS no.: 57-13-6), triethanolamine $\left(M_{w}: 149.19 \mathrm{~g} / \mathrm{mol}\right.$, CAS no.: 102-71-6), benzyl alcohol $\left(M_{w}: 108.13 \mathrm{~g} / \mathrm{mol}\right.$, CAS no.: 100-51-6), sodium dodecyl benzene sulfonate $\left(M_{w}: 348.48 \mathrm{~g} / \mathrm{mol}\right.$, CAS no.: 25155-30-0), citric acid monohydrate $\left(M_{w}: 210.14 \mathrm{~g} / \mathrm{mol}\right.$, CAS no.: 5949-29-1), octanol $\left(M_{w}: 130.23 \mathrm{~g} / \mathrm{mol}\right.$, CAS no.: 111-87-5), ethyl acetate $\left(M_{w}: 88.11 \mathrm{~g} / \mathrm{mol}\right.$, CAS no.: 141-78-6), and anhydrous alcohol $\left(M_{w}: 46.07 \mathrm{~g} / \mathrm{mol}\right.$, CAS no.: 64-17-5) were purchased from Xilong Chemical Co. Ltd., Guangzhou, China. Formaldehyde solution (formaldehyde content $37 \%, M_{w}: 30.03 \mathrm{~g} / \mathrm{mol}$, CAS no.: 50-00-0) was purchased from Guangdong Guanghua Sci-Tech Co. Ltd., Shantou, China. Epoxy resin $\left(M_{w}: 375.86 \mathrm{~g} / \mathrm{mol}\right.$, CAS no.: 61788-97-4) was purchased from Nantong Xingchen Synthetic Material Co. Ltd., Nantong, China.

2.2. Methods. Preparation of urea formaldehyde-coated epoxy resin microcapsules was composed of three processes [8]: preparation of the urea formaldehyde prepolymer (the wall material), preparation of the epoxy resin emulsion (the core material), and microencapsulation [9].

2.2.1. Preparation of the Urea Formaldehyde Prepolymer. The mixture of urea and formaldehyde solution was added to the beaker at the mass ratio of $1.00: 1.85$. The mixture was mixed well, and the $\mathrm{pH}$ of the solution was slowly adjusted to $8.0-9.0$ by adding triethanolamine. The mixture was continuously stirred for $1 \mathrm{~h}$ in a constant temperature water bath at $70^{\circ} \mathrm{C}$, and the wall material solution was prepared and cooled at room temperature.

2.2.2. Preparation of Epoxy Resin Emulsion for Core Material. The epoxy resin and benzyl alcohol (as diluent) were added to the beaker to be mixed completely. The mass ratio of benzyl alcohol to epoxy resin was fixed at 0.15:1. Certain amounts of deionized water and sodium dodecyl benzene sulfonate (emulsifier) were placed in another beaker for the emulsifier solution. Then the diluted epoxy resin solution was poured into the emulsifier solution and mixed, and the beaker was put into the water bath. In the water bath, the temperature was adjusted to $60^{\circ} \mathrm{C}$, then the agitator was set for $30 \mathrm{~min}$, and the core material emulsion was obtained by dropping in octanol for defoaming.

2.2.3. Microencapsulation [10]. At a certain speed, the wall urea formaldehyde resin was slowly added to the core material and the citric acid monohydrate was added to adjust the solution $\mathrm{pH}$ to 2.5-3.0. Then the water bath was slowly heated to $70^{\circ} \mathrm{C}$, and stirring continued for $3 \mathrm{~h}$. The product was allowed to stand for $0-48 \mathrm{~h}$, then washed with deionized water and anhydrous ethanol, and filtered. The remaining product was heated to $40^{\circ} \mathrm{C}$ for $48 \mathrm{~h}$, and the white powder obtained was used for the microcapsules [11].

A $\mathrm{L}_{16}\left(4^{5}\right)$ orthogonal experiment with 5 factors and 4 levels was used to optimize the preparation of microcapsules. The 5 factors were the mass ratio of the core material to the wall material $\left(W_{\text {core }}: W_{\text {wall }}\right)(A)$, mass ratio of the emulsifier to the core material ( $\left.W_{\text {emulsifier }}: W_{\text {core }}\right)(B)$, stirring rate $(C)$, deposition time $(D)$, and mass ratio of the emulsifier solution to the core material ( $\left.W_{\text {emulsifier solution }}: W_{\text {core }}\right)(E)$; four levels are shown in Table 1. According to the designed orthogonal experimental parameters, the samples obtained were samples $1-16$ in Table 2 . The detailed list of amounts of materials was shown in Table 3.

The amounts of $20.00 \mathrm{~g}$ urea and $50.00 \mathrm{~g} 37 \%$ formaldehyde solution were fixed for all samples, and $30.00 \mathrm{~g}$ of urea formaldehyde (the wall material) was obtained according to equation (1). The amounts of the other reagents in sample 1 were as follows: $18.00 \mathrm{~g}$ epoxy resin, $2.70 \mathrm{~g}$ benzyl alcohol, $143.82 \mathrm{~g}$ deionized water, and $0.18 \mathrm{~g}$ sodium dodecyl benzene sulfonate.

$$
\mathrm{H}_{2} \mathrm{~N}-\mathrm{CO}-\mathrm{NH}_{2}+\mathrm{HCHO} \rightarrow \mathrm{H}-\left[\mathrm{NH}-\mathrm{CO}-\mathrm{NH}-\mathrm{CH}_{2}\right]-\mathrm{OH}
$$

Epoxy resin $(10.00 \mathrm{~g}$ ) and $1.50 \mathrm{~g}$ benzyl alcohol were mixed until becoming smooth, then $0.53 \mathrm{~g}, 1.11 \mathrm{~g}, 1.76 \mathrm{~g}$, or $2.50 \mathrm{~g}$ microcapsules were added to make $5.0 \%, 10.0 \%$, $15.0 \%$, and $20.0 \%$ microcapsule concentrations of the mixture, respectively, and then the mixture was poured into the standard polytetrafluoroethylene dye. After vacuum drying for defoaming, the mixture was cured at room temperature for $12 \mathrm{~h}$ and then dried at $40^{\circ} \mathrm{C}$ for $10 \mathrm{~h}$ and at $80^{\circ} \mathrm{C}$ for $2 \mathrm{~h}$ and the mixture was demolded as microcapsule specimens for the repair rate test.

2.3. Characterization. The tensile strength of the material was analyzed by a microcomputer-controlled electronic universal testing machine, CMT6104, MTS Systems Corporation. The microstructure of the microcapsules was analyzed using a Quanta 200 environment scanning electron microscope (SEM), FEI Company, and L2800 Biomicroscope, Guangzhou Liss Optical Instrument Co. Ltd. The components of the microcapsules were analyzed using a Nicolet iS5 infrared spectrometer, Thermo Nicolet Corporation. The microcapsule powder was directly weighed after drying to test the yield of the microcapsules. Then $1.0 \mathrm{~g}$ microcapsules were put into a funnel and soaked in ethyl acetate, the ethyl acetate being replaced every $24 \mathrm{~h}$. The residual was washed with deionized water after $72 \mathrm{~h}$ soaking in ethyl 
TABLE 1: Influencing factors and levels.

\begin{tabular}{lccccc}
\hline Level & $W_{\text {core }}: W_{\text {wall }}$ & $W_{\text {emulsifier }}: W_{\text {core }}$ & Stirring rate $(\mathrm{r} / \mathrm{min})$ & Deposition time $(\mathrm{h})$ & $W_{\text {emulsifier solution }}: W_{\text {core }}$ \\
\hline 1 & $0.6: 1$ & $1: 100$ & 400 & 0 & $8: 1$ \\
2 & $0.8: 1$ & $3: 100$ & 600 & 16 & $9: 1$ \\
3 & $1.0: 1$ & $5: 100$ & 800 & 32 & $10: 1$ \\
4 & $1.2: 1$ & $7: 100$ & 1000 & 48 & $11: 1$ \\
\hline
\end{tabular}

TABLE 2: Experimental arrangements.

\begin{tabular}{|c|c|c|c|c|c|}
\hline Sample & $W_{\text {core }}: W_{\text {wall }}$ & $W_{\text {emulsifier }}: W_{\text {core }}$ & Stirring rate $(\mathrm{r} / \mathrm{min})$ & Deposition time $(\mathrm{h})$ & $W_{\text {emulsifier solution }}: W_{\text {core }}$ \\
\hline 1 & $0.6: 1$ & $1: 100$ & 400 & 0 & $8: 1$ \\
\hline 2 & $0.6: 1$ & $3: 100$ & 600 & 16 & $9: 1$ \\
\hline 3 & $0.6: 1$ & $5: 100$ & 800 & 32 & $10: 1$ \\
\hline 4 & $0.6: 1$ & $7: 100$ & 1000 & 48 & $11: 1$ \\
\hline 5 & $0.8: 1$ & $1: 100$ & 600 & 32 & $11: 1$ \\
\hline 6 & $0.8: 1$ & $3: 100$ & 400 & 48 & $10: 1$ \\
\hline 7 & $0.8: 1$ & $5: 100$ & 1000 & 0 & $9: 1$ \\
\hline 8 & $0.8: 1$ & $7: 100$ & 800 & 16 & $8: 1$ \\
\hline 9 & $1.0: 1$ & $1: 100$ & 800 & 48 & $9: 1$ \\
\hline 10 & $1.0: 1$ & $3: 100$ & 400 & 32 & $8: 1$ \\
\hline 11 & $1.0: 1$ & $5: 100$ & 1000 & 16 & $11: 1$ \\
\hline 12 & $1.0: 1$ & $7: 100$ & 600 & 0 & $10: 1$ \\
\hline 13 & $1.2: 1$ & $1: 100$ & 1000 & 16 & $10: 1$ \\
\hline 14 & $1.2: 1$ & $3: 100$ & 800 & 0 & $11: 1$ \\
\hline 15 & $1.2: 1$ & $5: 100$ & 600 & 48 & $8: 1$ \\
\hline 16 & $1.2: 1$ & $7: 100$ & 400 & 32 & $9: 1$ \\
\hline 17 & $0.8: 1$ & $1: 100$ & 600 & 32 & $8: 1$ \\
\hline
\end{tabular}

TABle 3: Detailed list of amounts of materials.

\begin{tabular}{lcccc}
\hline Sample & $\begin{array}{c}\text { Epoxy } \\
\text { resin }(\mathrm{g})\end{array}$ & $\begin{array}{c}\text { Benzyl } \\
\text { alcohol } \\
(\mathrm{g})\end{array}$ & $\begin{array}{c}\text { Sodium dodecyl } \\
\text { benzene sulfonate }(\mathrm{g})\end{array}$ & $\begin{array}{c}\text { Deionized } \\
\text { water }(\mathrm{g})\end{array}$ \\
\hline 1 & 18.00 & 2.70 & 0.18 & 143.82 \\
2 & 18.00 & 2.70 & 0.54 & 161.46 \\
3 & 18.00 & 2.70 & 0.90 & 179.10 \\
4 & 18.00 & 2.70 & 1.26 & 196.74 \\
5 & 24.00 & 3.60 & 0.72 & 263.76 \\
6 & 24.00 & 3.60 & 1.20 & 239.28 \\
7 & 24.00 & 3.60 & 1.68 & 214.80 \\
8 & 24.00 & 3.60 & 2.16 & 190.32 \\
9 & 30.00 & 4.50 & 0.30 & 269.70 \\
10 & 30.00 & 4.50 & 0.90 & 239.10 \\
11 & 30.00 & 4.50 & 1.50 & 328.50 \\
12 & 30.00 & 4.50 & 2.10 & 297.90 \\
13 & 36.00 & 5.40 & 0.36 & 359.64 \\
14 & 36.00 & 5.40 & 1.08 & 394.92 \\
15 & 36.00 & 5.40 & 1.80 & 286.20 \\
16 & 36.00 & 5.40 & 2.52 & 321.48 \\
17 & 24.00 & 3.60 & 0.24 & 191.76 \\
\hline
\end{tabular}

acetate and dried, and the material obtained was the wall material. The coverage rate was calculated by the following:

$$
C=\frac{\left(m_{1}-m_{2}\right)}{m_{1}} * 100 \% .
$$

In formula (2), $C$ is the coverage rate of microcapsules (the content of the capsule core), $m_{1}$ is the initial mass of microcapsules, and $m_{2}$ is the quality of the residual wall material after soaking. The microcapsules were added to the epoxy resin to make the specimen, and the tensile test was used to characterize the repair rate. To prepare specimens to test the repair rate of microcapsules, $10.0 \mathrm{~g}$ epoxy resin and $1.50 \mathrm{~g}$ benzyl alcohol were mixed completely, then $1.20 \mathrm{~g}$ of the microcapsule powder was added, and two identical specimens, A and B, were prepared. The tensile tests were carried out at the tensile rate of $2 \mathrm{~mm} / \mathrm{min}$. Tensile tests for specimen A were carried out until the breaking force was obtained. The maximum breaking force of specimen A was the initial maximum fracture force. The maximum tensile force of specimen $B$ was set to $70 \%$ of the initial maximum fracture force of specimen $\mathrm{A}$; then specimen $\mathrm{B}$ was put into the oven at $80^{\circ} \mathrm{C}$ for $2 \mathrm{~h}$. Then the tensile test for specimen $B$ was carried out until the maximum fracture force was obtained, that is, the maximum fracture force after repair 


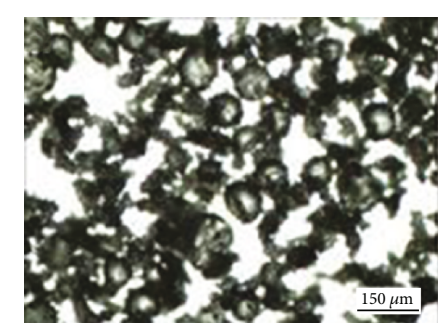

(a)

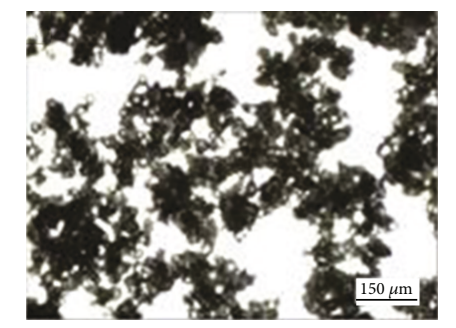

(c)

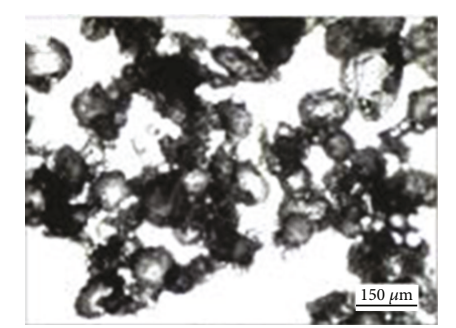

(e)

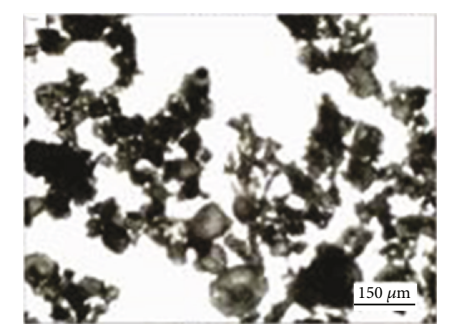

(g)

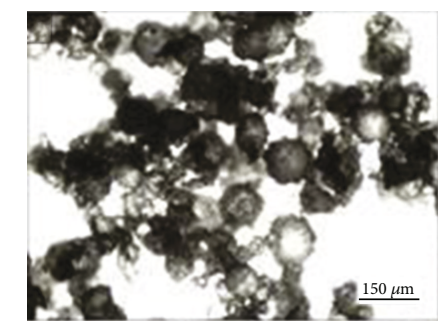

(i)

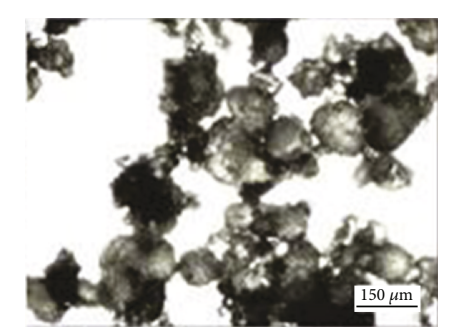

(k)

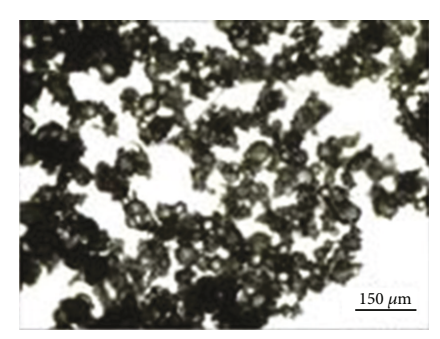

(b)

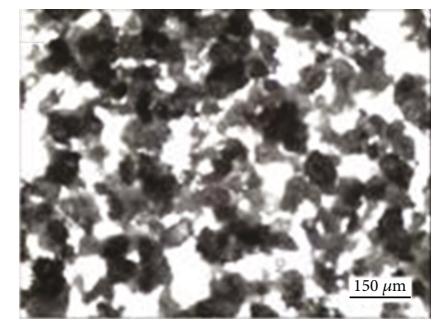

(d)

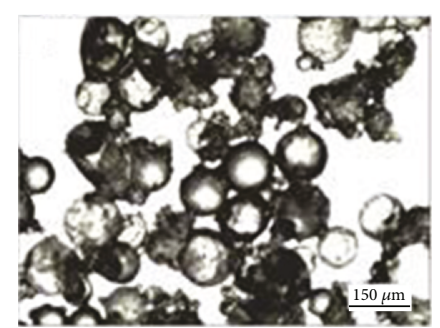

(f)

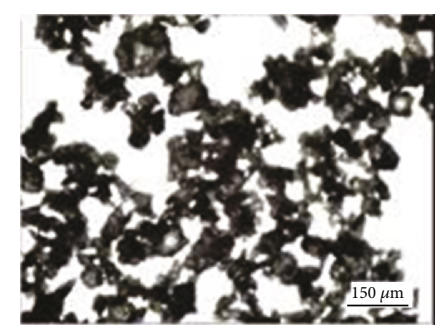

(h)

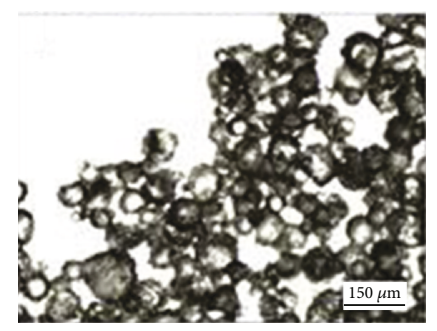

(j)

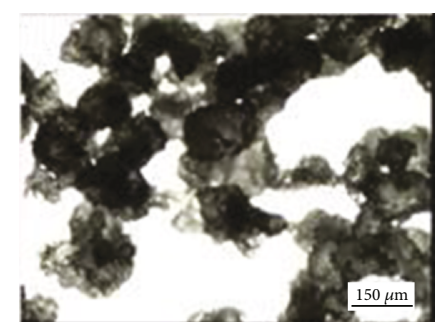

(l)

Figure 1: Continued. 


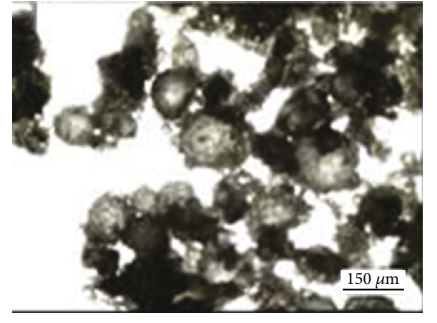

(m)

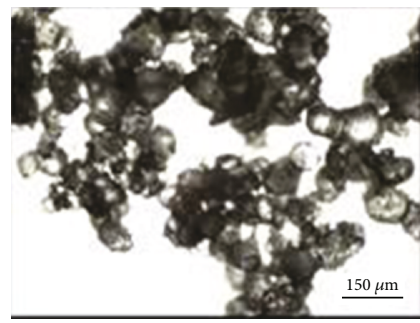

(o)

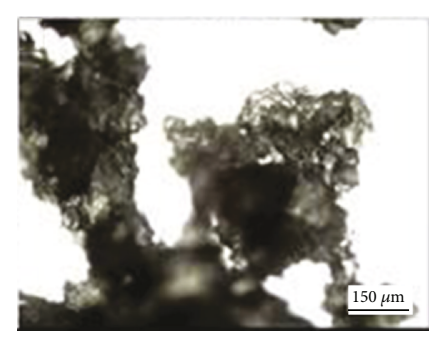

(n)

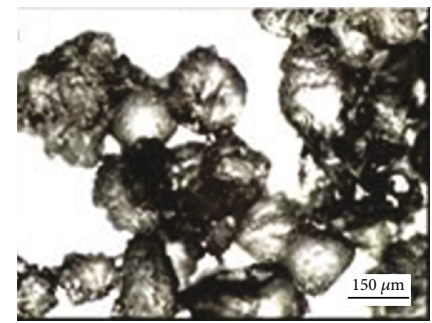

(p)

FIGURE 1: Surface morphology of samples 1-16 in Table 2.

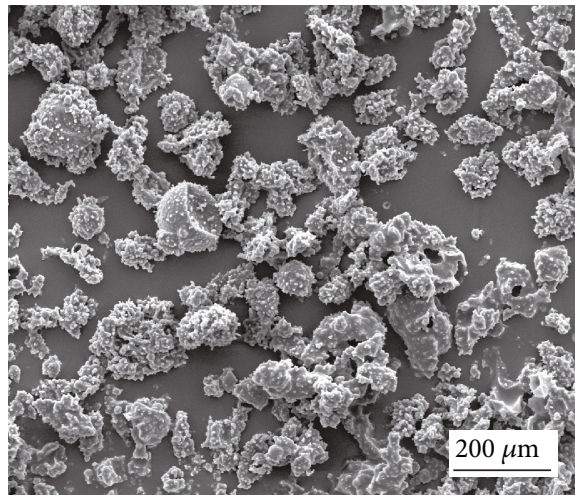

(a)

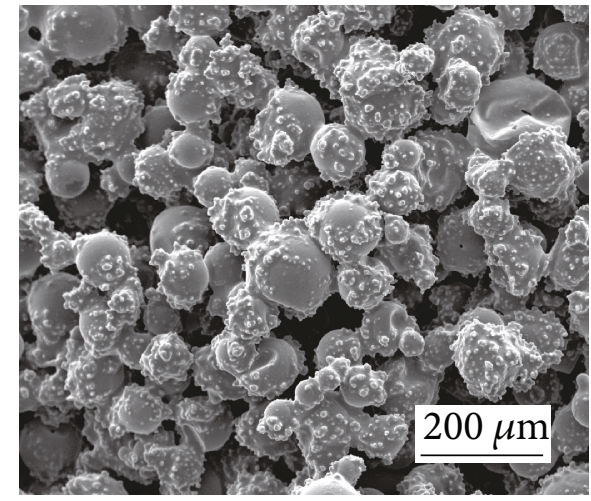

(b)

FIgURE 2: SEM of samples 8 and 10.

was obtained. The ratio of the maximum fracture force of specimen B to specimen A (formula (3)) was used to calculate the repair rate:

$$
\eta=\frac{P_{r}}{P_{0}} * 100 \% .
$$

In formula (3), $\eta$ is the repair rate, $P_{r}$ is the maximum fracture force after repair, and $P_{0}$ is the initial maximum fracture force of the specimen. The calculation method of repair rates with $5.0 \%, 10.0 \%, 15.0 \%$, and $20.0 \%$ microcapsule concentrations was the same as above, except that the quality of the microcapsules was different. All the experiments were repeated four times with an error of less than $5.0 \%$.

\section{Results and Discussions}

3.1. Structure and Performance Characteristics of Microcapsules. The morphologies of A-P shown in Figure 1 correspond to microcapsules prepared by the orthogonal experiments (samples 1-16 in Table 2). Most of the samples in Figure 1 were successfully encapsulated. Samples 4, $7,8,12$, and 14 were not encapsulated due to an improper mass ratio or high stirring rate, which was not conducive to form the microcapsules. Microcapsule samples 6 and 10 were better. The microcapsule surface of these two samples was slightly rough, and the particle size was more uniform. Thus, the urea formaldehyde-coated epoxy resin microcapsule [12] with a particle size of about $100 \mu \mathrm{m}$ was successfully prepared.

SEM of the uncoated microcapsules and encapsulated intact microcapsules was performed, and samples 8 and 10 were photographed, as shown in Figure 2. The microcapsules of sample 10 were regular spheres with a rough surface and uniform size. Sample 8 exhibited irregular precipitation and an uneven surface. It can be seen that sample 10 has a good morphology and encapsulation and the preparation factors and levels of the sample 10 microcapsule can be used as reference criteria for optimization [13].

Figure 3 is the infrared spectrum of sample 6 and sample 10 microcapsules in the orthogonal experiment. The 


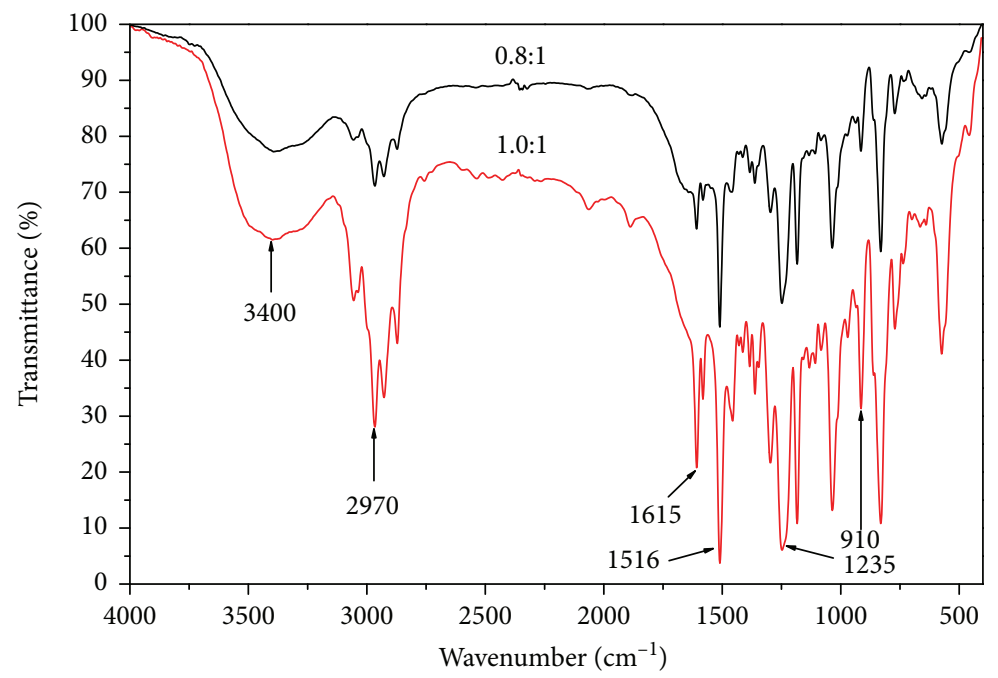

Figure 3: Infrared spectra of microcapsules of sample $6\left(W_{\text {core }}: W_{\text {wall }}=0.8: 1\right)$ and sample $10\left(W_{\text {core }}: W_{\text {wall }}=1.0: 1\right)$.

attribution of the peak is shown in Table 4. The absorption peaks were basically the same, indicating that the chemical components are the same. The $W_{\text {core }}: W_{\text {wall }}$ ratios were $0.8: 1$ and $1.0: 1$ for sample 6 and sample 10, respectively. Figure 3 shows $3400 \mathrm{~cm}^{-1}, 2970 \mathrm{~cm}^{-1}, 1615 \mathrm{~cm}^{-1}$, and $1516 \mathrm{~cm}^{-1}$ stretching vibration absorption peaks of the $\mathrm{N}-\mathrm{H}$, $\mathrm{C}-\mathrm{H}, \mathrm{C}=\mathrm{O}$, and $\mathrm{C}-\mathrm{N}$ bonds, respectively [14]. The characteristic peaks that can be seen in microcapsule samples 6 and 10 indicate that a urea formaldehyde resin has been formed. The expansion vibrations of C-O in epoxy resin were $1249 \mathrm{~cm}^{-1}$ and $916 \mathrm{~cm}^{-1}$, respectively. It was found that the chemical structure of epoxy resin did not change and the epoxy resin was coated by urea formaldehyde resin [15].

3.2. Orthogonal Experimental Results. The yield, coverage rate, and repair rate of samples $1-16$ in Table 2 were calculated as shown in Table 5. According to Table 5, the yield of sample 10 was the highest, reaching $40.82 \mathrm{~g}$. The yield of sample 14 was the lowest, only $5.94 \mathrm{~g}$. The coverage rate of sample 16 was the highest, reaching $85 \%$, while the coverage rate of sample 14 was the lowest, only $25 \%$. The repair rate of sample 5 was the highest, reaching $107.6 \%$, and the repair rate of sample 14 was the lowest, only $68.72 \%$. According to the above results, it can be concluded that the yield, coverage rate, and repair rate of sample 14 were the lowest. Sample 14 was not successfully encapsulated, with the surface morphology shown in Figure 1; therefore, the coverage rate and repair effect of sample 14 were poor. Samples 5, 10, and 16 had the highest repair rate, highest yield, and the highest coverage rate, respectively. However, the microscopic image in Figure 1 shows that although the coverage rate of sample 16 was high, the agglomeration rate was more serious, so it cannot be used only as a reference for the successful preparation of the microcapsules. In order to obtain the best preparation process parameters, the best microcapsule can be obtained by considering and combining the comprehensive information.

The yield of microcapsules is an important basis for judging whether microcapsules can be used in the indus-
TABle 4: Assignment of peaks.

\begin{tabular}{lc}
\hline Peak $\left(\mathrm{cm}^{-1}\right)$ & Assignment \\
\hline 3400 & N-H stretching vibration \\
2970 & C-H stretching vibration \\
1615 & $\mathrm{C}=\mathrm{O}$ stretching vibration \\
1516 & $\mathrm{C}-\mathrm{N}$ stretching vibration \\
1249,916 & Expansion vibration of C-O in epoxy resin \\
\hline
\end{tabular}

TABLE 5: Orthogonal experiment design results.

\begin{tabular}{lccc}
\hline Sample & Yield $(\mathrm{g})$ & Coverage rate $(\%)$ & Repair rate $(\%)$ \\
\hline 1 & 26.17 & 74.00 & 105.50 \\
2 & 23.69 & 48.00 & 91.20 \\
3 & 31.01 & 48.00 & 100.40 \\
4 & 13.10 & 35.00 & 77.80 \\
5 & 29.01 & 65.00 & 107.60 \\
6 & 25.43 & 78.00 & 105.60 \\
7 & 8.49 & 63.00 & 95.03 \\
8 & 27.81 & 58.00 & 98.20 \\
9 & 36.12 & 71.00 & 74.20 \\
10 & 40.82 & 78.00 & 106.20 \\
11 & 6.48 & 45.00 & 74.37 \\
12 & 22.34 & 80.00 & 98.30 \\
13 & 11.56 & 60 & 72.07 \\
14 & 5.94 & 25 & 68.72 \\
15 & 23.76 & 77 & 94.50 \\
16 & 39.68 & 85 & 93.30 \\
\hline
\end{tabular}

try. Using the smallest amount of materials to prepare more microcapsules is desirable. Therefore, the range analysis and remarkable analysis of the yield are very important. According to the yield calculation results of the orthogonal experimental microcapsules [16], Tables 6 and 7 show that the main sequence of the technological 
TABLE 6: Range of microcapsule yields.

\begin{tabular}{lccccc}
\hline Mean value & $W_{\text {core }}: W_{\text {wall }}$ & $W_{\text {emulsifier }}: W_{\text {core }}$ & Stirring rate & Deposition time & $W_{\text {emulsifier solution }}: W_{\text {core }}$ \\
\hline Mean value 1 & 23.492 & 25.715 & 24.440 & 15.735 & 17.385 \\
Mean value 2 & 22.685 & 23.970 & 24.700 & 35.130 & 26.995 \\
Mean value 3 & 26.440 & 17.435 & 25.220 & 24.603 & 22.585 \\
Mean value 4 & 20.235 & 25.733 & 18.492 & 19.395 & 13.633 \\
Range & 6.205 & 8.298 & 6.728 & 16.007 \\
\hline
\end{tabular}

TABLE 7: Remarkable analysis of microcapsule yields.

\begin{tabular}{lcccc}
\hline Factor & Sum of squares of deviations & Freedom & $F$ ratio & $F$ critical value \\
\hline$W_{\text {core }}: W_{\text {wall }}$ & 78.556 & 3 & 1.000 & 9.280 \\
$W_{\text {emulsifier }}: W_{\text {core }}$ & 186.265 & 3 & 2.371 & 9.280 \\
Stirring rate & 120.111 & 3 & 1.529 & 9.280 \\
Deposition time & 935.327 & 3 & 11.906 & 9.280 \\
$W_{\text {emulsifier solution }}: W_{\text {core }}$ & 591.161 & 3 & 7.525 & 9.280 \\
Error & 78.56 & 3 & & $*$ \\
\hline
\end{tabular}

TABLE 8: Range of coverage rates of microcapsules.

\begin{tabular}{lccccc}
\hline Mean value & $W_{\text {core }}: W_{\text {wall }}$ & $W_{\text {emulsifier }}: W_{\text {core }}$ & Stirring rate & Deposition time & $W_{\text {emulsifier solution }}: W_{\text {core }}$ \\
\hline Mean value 1 & 51.250 & 67.500 & 70.500 & 60.500 & 71.750 \\
Mean value 2 & 66.000 & 57.250 & 67.500 & 52.750 & 66.750 \\
Mean value 3 & 68.500 & 58.250 & 50.500 & 69.000 & 66.500 \\
Mean value 4 & 61.750 & 64.500 & 59.000 & 65.250 & 42.500 \\
Range & 17.250 & 10.250 & 20.000 & 16.250 & 29.250 \\
\hline
\end{tabular}

conditions affecting the urea formaldehyde-coated epoxy resin microcapsules was $D>E>B>C>A$ and the effect of the $D$ factors was remarkable. The effect of deposition time on the yield is more significant, which is probably due to the slow formation of the microcapsules during the deposition. The best condition for preparation of the urea formaldehyde-coated epoxy resin microcapsules was $A_{3} B_{4}$ $C_{3} D_{3} E_{1}$, that is, $W_{\text {core }}: W_{\text {wall }}$ was $1: 1, W_{\text {emulsifier }}: W_{\text {core }}$ was $7: 100$, the stirring rate was $800 \mathrm{r} / \mathrm{min}$, the deposition time was $32 \mathrm{~h}$, and $W_{\text {emulsifier solution }}: W_{\text {core }}$ was $8: 1$.

The coverage rate of microcapsules is closely related to the content of the microcapsule core and the repair rate of microcapsules. The range analysis and remarkable analysis of the coverage rate were calculated as shown in Tables 8 and 9. According to the calculation of the repair rates of the orthogonal experiment, the main sequence of the coverage rate affecting the urea formaldehyde-coated epoxy resin microcapsules was $E>C>A>D>B$. The mass ratio of the emulsifier solution to the core material has a great influence on the coverage rate, which may be due to the importance of proper emulsification to the high coverage rate. The optimum combination of the process conditions for preparing the urea formaldehyde-coated epoxy resin microcapsules was $A_{3} B_{1} C_{1} D_{3} E_{1}$, that is $W_{\text {core }}: W_{\text {wall }} 1: 1$, $W_{\text {emulsifier }}: W_{\text {core }} 1: 100$, stirring rate $400 \mathrm{r} / \mathrm{min}$, the deposition time $32 \mathrm{~h}$, and $W_{\text {emulsifier solution }}: W_{\text {core }} 8: 1$.
The repair rate of microcapsules is an indication of the repair power of microcapsules for epoxy resin. The higher the repair rate, the better the repair ability of microcapsules in materials. Therefore, range analysis and remarkable analysis of the repair rate are very important. According to the calculations of the repair rate of the orthogonal experimental microcapsules, the main sequence of the conditions affecting the repair rate of microcapsules was shown by Tables 10 and 11 . The main sequence affecting the repair rate was $A>E>D>C>B$. Factors $A$, $C, D$, and $E$ were remarkable factors for the repair rate. The mass ratio of the core to wall material seriously affects the repair rate of microcapsules. When the mass of the core material is low, the repair rate is not good. However, if the mass of the core material is too high, the coverage rate may be reduced, which will also affect the repair rate. The optimum technological condition for preparing the urea formaldehyde-coated epoxy resin microcapsule was $A_{2} B_{2} C_{2} D_{3} E_{1}$, which was $W_{\text {core }}: W_{\text {wall }} 0.8: 1, W_{\text {emulsifier }}$ : $W_{\text {core }} 3: 100$, stirring rate $600 \mathrm{r} / \mathrm{min}$, the deposition time $32 \mathrm{~h}$, and $W_{\text {emulsifier solution }}: W_{\text {core }} 8: 1$.

Figure 4 is a diagram of the effects of $A, B, C, D$, and $E$ on the yield, coverage rate, and repair rate of microcapsules. It can be seen clearly that factor A has the most significant effect on the repair rate [17]. Factors $D$ and $E$ have significant effects on yield, and factor $E$ has the most 
TABLE 9: Remarkable analysis of coverage rates of microcapsules.

\begin{tabular}{lcccc}
\hline Factor & Sum of squares of deviations & Freedom & $F$ ratio & $F$ critical value \\
\hline$W_{\text {core }}: W_{\text {wall }}$ & 695.250 & 3 & 2.379 & 9.280 \\
$W_{\text {emulsifier }}: W_{\text {core }}$ & 292.250 & 3 & 1.000 & 9.280 \\
Stirring rate & 974.750 & 3 & 3.335 & 9.280 \\
Deposition time & 589.250 & 3 & 2.016 & 9.280 \\
$W_{\text {emulsifier solution }}: W_{\text {core }}$ & 2072.250 & 3 & 7.091 & 9.280 \\
Error & 292.250 & 3 & & \\
\hline
\end{tabular}

TABLE 10: Range of repair rates of microcapsules.

\begin{tabular}{lccccc}
\hline Mean value & $W_{\text {core }}: W_{\text {wall }}$ & $W_{\text {emulsifier }}: W_{\text {core }}$ & Stirring rate & Deposition time & $W_{\text {emulsifier solution }}: W_{\text {core }}$ \\
\hline Mean value 1 & 93.725 & 89.843 & 94.693 & 91.887 & 101.100 \\
Mean value 2 & 101.608 & 92.930 & 97.900 & 83.960 & 88.433 \\
Mean value 3 & 88.267 & 91.075 & 85.380 & 101.875 & 94.093 \\
Mean value 4 & 82.147 & 91.900 & 87.775 & 88.025 & 82.123 \\
Range & 19.461 & 3.087 & 12.520 & 17.915 & 18.977 \\
\hline
\end{tabular}

TABLE 11: Remarkable analysis of repair rates of microcapsules.

\begin{tabular}{|c|c|c|c|c|c|}
\hline Factor & Sum of squares of deviations & Freedom & $F$ ratio & $F$ critical value & Saliency \\
\hline$W_{\text {core }}: W_{\text {wall }}$ & 820.058 & 3 & 40.065 & 9.280 & * \\
\hline$W_{\text {emulsifier }}: W_{\text {core }}$ & 20.468 & 3 & 1.000 & 9.280 & \\
\hline Stirring rate & 409.865 & 3 & 20.025 & 9.280 & $*$ \\
\hline Deposition time & 706.808 & 3 & 34.532 & 9.280 & * \\
\hline$W_{\text {emulsifier solution }}: W_{\text {core }}$ & 784.849 & 3 & 38.345 & 9.280 & $*$ \\
\hline Error & 20.47 & 3 & & & \\
\hline
\end{tabular}

significant effect on the coverage rate. According to the analysis and calculation of the yield, coverage rate, and repair rate of the microcapsules, the optimum combination of the preparation of urea formaldehyde-coated epoxy resin microcapsules was $A_{3} B_{4} C_{3} D_{3} E_{1}, A_{3} B_{1} C_{1} D_{3} E_{1}$, and $A_{2} B_{2} C_{2} D_{3} E_{1}$. Because the optimum levels of factors $D$ and $E$ on the yield, coverage rate, and repair rate of microcapsules were the same, the level of $D_{3} E_{1}$ was selected. Factor $A$ has a prominent effect on the repair rate; therefore, level $A_{2}$ was selected [18]. Factor $B$ has a great effect on the coverage rate; therefore, level $B_{1}$ with the smallest $W_{\text {emulsifier }}: W_{\text {core }}$ was selected. The effect of $C$ on the coverage rate was more significant, so level $C_{1}$ was chosen. Therefore, a comprehensive analysis showed that the optimal parameters for preparing urea formaldehyde-coated epoxy resin microcapsules was $A_{2} B_{1} C_{1} D_{3} E_{1}$, that is, $W_{\text {core }}: W_{\text {wall }} 0.8: 1, W_{\text {emulsifier }}: W_{\text {core }}$ $1: 100$, stirring rate $600 \mathrm{r} / \mathrm{min}$, the deposition time $32 \mathrm{~h}$, and $W_{\text {emulsifier solution }}: W_{\text {core }} 8: 1$.

3.3. Self-Repairing Properties. Figure 5 is an SEM image of the optimized preparation of microcapsules. The microcapsules shown in Figure 5 were successfully coated with urea formaldehyde resin, forming urea formaldehyde-coated epoxy resin microcapsules with a uniform particle size

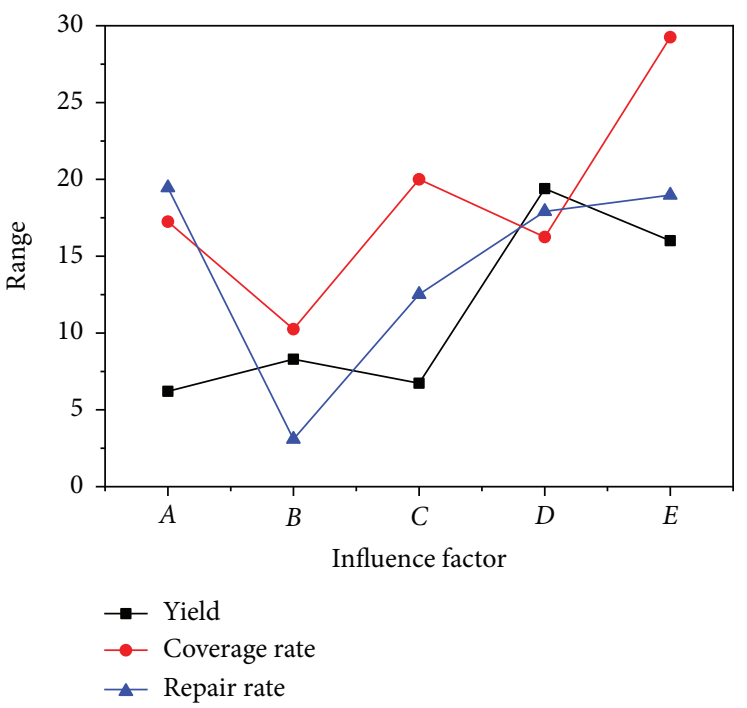

FIGURE 4: Range of effects of factors on yield, coverage rate, and repair rate.

distribution and rough shell. Compared with microcapsules 1-16 in the orthogonal experiment, the morphology of the microcapsules had very little superfluous sediment 


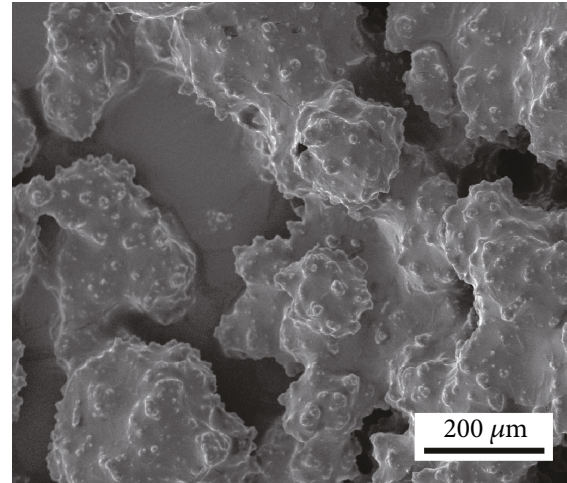

(a)

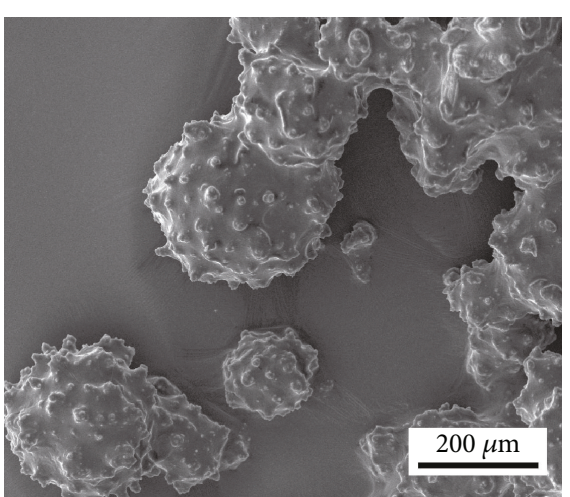

(b)

FIgURE 5: SEM image of the best microcapsule (sample 17).

and few damaged microcapsules and the optimized microcapsules were improved.

The particle size of the microcapsules was measured using ImageJ software [19]. The average particle size of the microcapsules was $109.414 \mu \mathrm{m}$, and the size distribution diagram of the microcapsules is shown as Figure 6. The size distribution of microcapsules was in the range of 60 $190 \mu \mathrm{m}$, mainly in the $80-140 \mu \mathrm{m}$ interval, indicating that the optimized microcapsules had a larger span in the particle size distribution but that the distribution of the microcapsules was relatively uniform.

Table 12 shows that the yield of microcapsules after optimization was $45.63 \mathrm{~g}$ and the coverage rate was $75 \%$. The maximum tensile strength of the epoxy resin was $30.64 \mathrm{~N} / \mathrm{mm}^{2}$, and the maximum tensile strength after repair with microcapsules was $34.59 \mathrm{~N} / \mathrm{mm}^{2}$. The repair rate of the microcapsules was $113.04 \%$ after optimization. Compared with samples 1-16 in Table 2, the yield and repair rate of the optimized microcapsules were the highest of all the samples, indicating that the optimized microcapsules had a further improvement in the yield and repair rate. In addition, the coverage rate of the optimized microcapsule was $75 \%$; although this was not the highest, it compared favorably with the best comprehensive performance of samples 6 and 10 microcapsules $(78 \%)$ in the orthogonal experiment and the difference was only $3 \%$ less. Therefore, the comprehensive performance of the optimized microcapsule was better than that of the orthogonal experiment [20].

In order to further verify the effect of the different concentrations of microcapsules on self-repair properties, the optimized microcapsules were added to the epoxy resin at $5.0 \%, 10.0 \%, 15.0 \%$, and $20.0 \%$ [21] and were shown in Figure 7 . When the concentration of epoxy resin increased from $5.0 \%$ to $10.0 \%$, the repair rate increased from $108.81 \%$ to $114.77 \%$. When the concentration of epoxy resin increased from $10.0 \%$ to $20.0 \%$, the repair rate decreased from $114.77 \%$ to $97.91 \%$. With the increasing concentration of epoxy resin in microcapsules, the repair rate first increased and then decreased and the repair rate reached the maximum when the concentration of epoxy resin in microcapsules was $10.0 \%$. Figure 8 shows SEM of the different concentrations of microcapsules added to the epoxy resin. At the

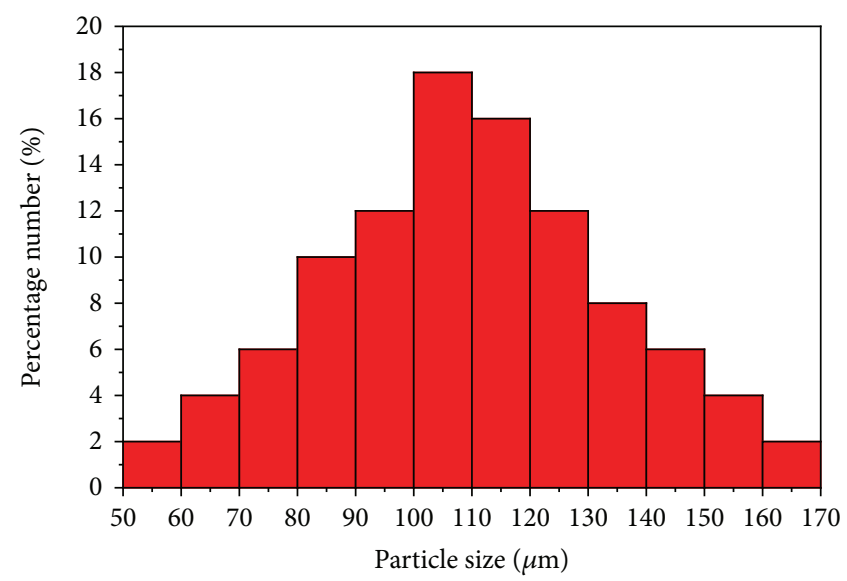

Figure 6: Particle size distribution of the best microcapsule.

TABLE 12: Comprehensive properties of microcapsules prepared by optimization.

\begin{tabular}{lccccc}
\hline Sample & $\begin{array}{c}\text { Yield } \\
(\mathrm{g})\end{array}$ & $\begin{array}{c}\text { Coverage rate } \\
(\%)\end{array}$ & $\begin{array}{c}P_{0} / N \\
\left(\mathrm{~mm}^{2}\right)\end{array}$ & $\begin{array}{c}P_{r} / N \\
\left(\mathrm{~mm}^{2}\right)\end{array}$ & $\begin{array}{c}\text { Repair rate } \\
(\%)\end{array}$ \\
\hline 17 & 45.63 & 75 & 30.64 & 34.59 & 113.04 \\
\hline
\end{tabular}

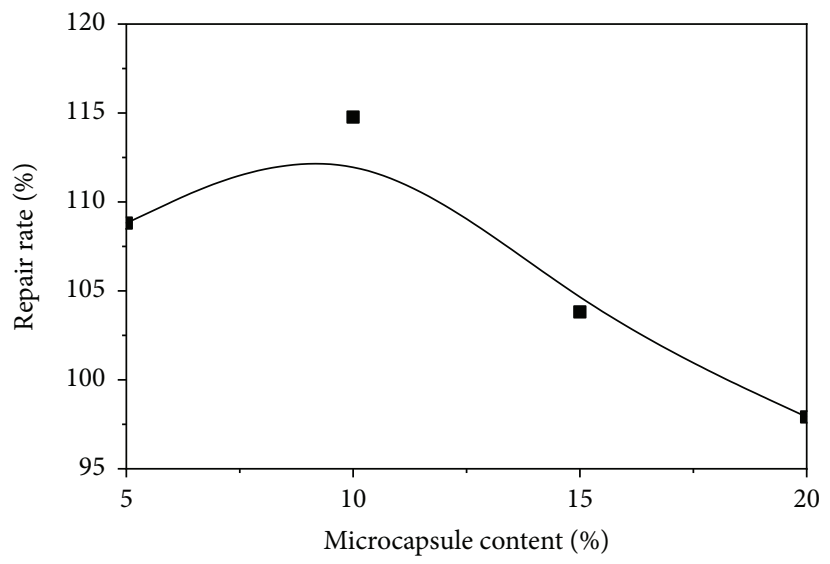

Figure 7: Repair rate of samples with different microcapsule concentrations. 


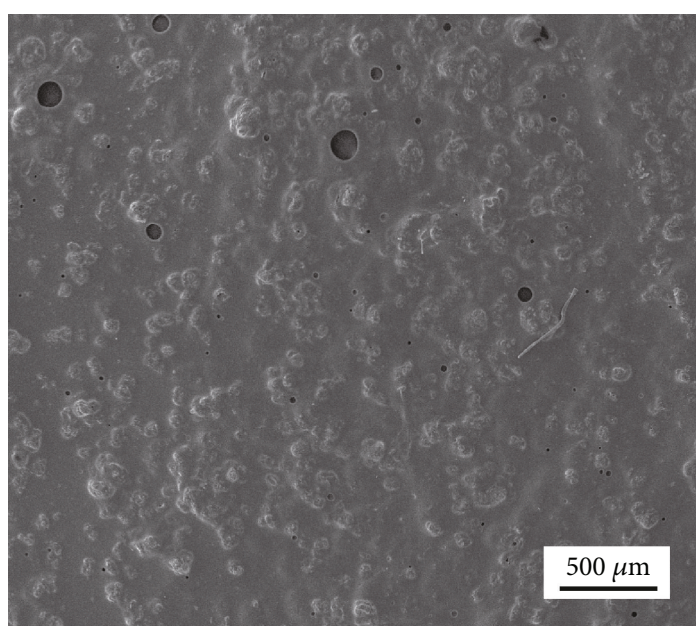

(a)

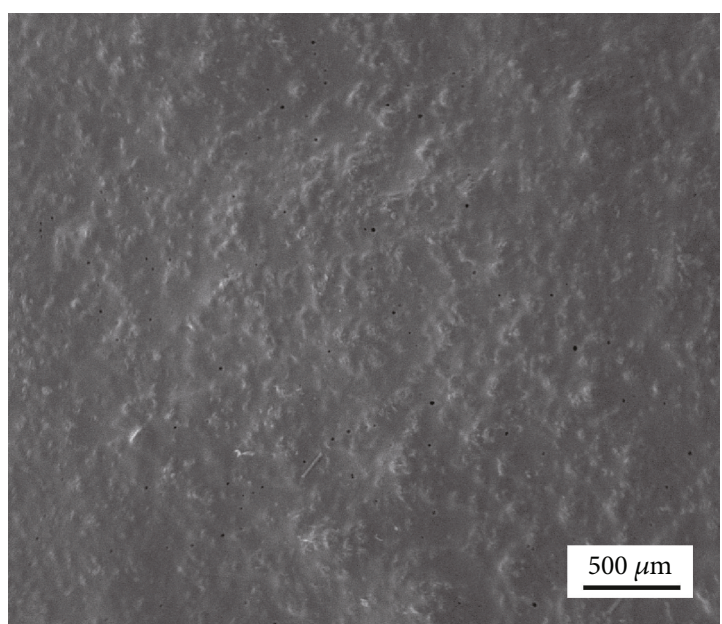

(b)

FIGURE 8: SEM of epoxy resin with $10.0 \%$ and $15.0 \%$ microcapsule concentrations.

concentration of $10 \%$, microcapsules can be evenly dispersed in the whole epoxy resin (Figure 8(a)) and the ability to repair was excellent, while a concentration of microcapsules greater than $10 \%$ would lead to agglomeration of the microcapsules (Figure 8(b)), which reduced the tensile strength of the microcapsules in the epoxy resin [22]. When the concentration of microcapsules was less than $10 \%$, the repair rate of the specimen did not reach the highest value. Therefore, when the concentration of microcapsules was $10.0 \%$, the best repair effect was achieved [23].

\section{Conclusion}

The surface morphology and chemical composition of microcapsules prepared by an orthogonal experiment were characterized by scanning electron microscopy and infrared spectroscopy. The results showed that microcapsules with a high coverage rate, high repair rate, and high yield were successfully prepared. Through the orthogonal experimental five factors and four levels, the morphology of the microcapsules and the range and remarkable analysis on the yield, the optimal repair rate and the coverage rate of microcapsules were elucidated. The optimum process parameters for preparing urea formaldehyde-coated epoxy resin microcapsules were obtained by $\mathrm{A}_{2} \mathrm{~B}_{1} \mathrm{C}_{1} \mathrm{D}_{3} \mathrm{E}_{1}$. When $W_{\text {core }}: W_{\text {wall }}$ was $0.8: 1$, $W_{\text {emulsifier }}: W_{\text {core }} 1: 100$, stirring rate $600 \mathrm{r} / \mathrm{min}$, the deposition time $32 \mathrm{~h}$, and $W_{\text {emulsifier solution }}: W_{\text {core }} 8: 1$, microcapsules with better morphology, a high encapsulation rate, higher repair rate, and higher yield were prepared. The effect of the addition of $5.0 \%, 10.0 \%, 15.0 \%$, and $20.0 \%$ microcapsules on the repair properties was studied, which revealed that the optimum concentration of microcapsules was $10.0 \%$ and the repair rate reached $114.77 \%$.

\section{Data Availability}

The raw/processed data required to reproduce these findings cannot be shared at this time as the data also forms part of an ongoing study.

\section{Conflicts of Interest}

The authors declare no competing financial interest.

\section{Acknowledgments}

This project is supported by the Natural Science Foundation of Jiangsu Province (BK20150887), Youth Science and Technology Innovation Fund of Nanjing Forestry University (CX2016018), and Priority Academic Program Development of Jiangsu Higher Education Institutions (PAPD).

\section{References}

[1] J. H. Song, X. F. Cui, Z. Liu et al., “Advanced microcapsules for self-healing conversion coating on magnesium alloy in $\mathrm{Ce}\left(\mathrm{NO}_{3}\right)_{3}$ solution with microcapsules containing $\mathrm{La}\left(\mathrm{NO}_{3}\right)_{3}$," Surface and Coatings Technology, vol. 307, pp. 500-505, 2016.

[2] P. A. Bolimowski, R. Kozera, and A. Boczkowska, "Poly(ureaformaldehyde) microcapsules - synthesis and influence of stirring speed on capsules size," Polimery, vol. 63, no. 5, pp. 339-346, 2018.

[3] X. X. Yan, Y. T. Cai, R. Lu, and T. Miyakoshi, "Development and characterization of new coating material of blended epoxy-lacquer with aluminum," International Journal of Polymer Science, vol. 2017, Article ID 5017356, 8 pages, 2017.

[4] T. Siva and S. Sathiyanarayanan, "Self healing coatings containing dual active agent loaded urea formaldehyde (UF) microcapsules," Progress in Organic Coating, vol. 82, pp. 5767, 2015.

[5] X. Y. Geng, W. Li, Y. Wang et al., "Reversible thermochromic microencapsulated phase change materials for thermal energy storage application in thermal protective clothing," Applied Energy, vol. 217, pp. 281-294, 2018.

[6] X. Wang, T. Jin, H. W. Wang, S. Z. Liao, and H. Y. Yang, "Preparation and characterization of polysulfide sealant microcapsules based on in situ polymerization of urea and formaldehyde," Chemical Journal of Chinese Universities-Chinese, vol. 39, no. 2, pp. 397-404, 2018. 
[7] S. M. Wu, L. Yuan, A. J. Gu, Y. Zhang, and G. Z. Liang, "Synthesis and characterization of novel epoxy resins-filled microcapsules with organic/inorganic hybrid shell for the self-healing of high performance resins," Polymers for Advanced Technologies, vol. 27, no. 12, pp. 1544-1556, 2016.

[8] F. H. Kong, W. C. Xu, X. L. Zhang, X. Wang, Y. Zhang, and J. L. Wu, "High-efficiency self-repairing anticorrosion coatings with controlled assembly microcapsules," Journal of Materials Science, vol. 53, no. 18, pp. 12850-12859, 2018.

[9] Q. X. Zhou, L. Yang, J. Xu et al., "Evaluation of the physicochemical stability and digestibility of microencapsulated esterified astaxanthins using in vitro and in vivo models," Food Chemistry, vol. 260, pp. 73-81, 2018.

[10] J. D. Hoyos-Leyva, L. A. Bello-Perez, and J. Alvarez-Ramirez, "Thermodynamic criteria analysis for the use of taro starch spherical aggregates as microencapsulant matrix," Food Chemistry, vol. 259, pp. 175-180, 2018.

[11] S. J. Wang, Y. Shi, and L. P. Han, "Development and evaluation of microencapsulated peony seed oil prepared by spray drying: oxidative stability and its release behavior during in-vitro digestion," Journal of Food Engineering, vol. 231, pp. 1-9, 2018.

[12] R. Ravanfar, T. A. Comunian, and A. Abbaspourrad, "Thermoresponsive, water-dispersible microcapsules with a lipidpolysaccharide shell to protect heat-sensitive colorants," Food Hydrocolloids, vol. 81, pp. 419-428, 2018.

[13] Y. Niu, L. Qi, F. Zhang, and Y. Zhao, "Geometric screening of core/shell hydrogel microcapsules using a tapered microchannel with interdigitated electrodes," Biosensors \& Bioelectronics, vol. 112, pp. 162-169, 2018.

[14] M. Liu, Y. Wang, Y. Q. Wu, and H. Wan, "Hydrolysis and recycling of urea formaldehyde resin residues," Journal of Hazardous Materials, vol. 355, pp. 96-103, 2018.

[15] H. A. Shnawa, M. N. Khalaf, and Y. Jahani, "Thermal degradation, dynamic mechanical and morphological properties of PVC stabilized with natural polyphenol-based epoxy resin," Polymer Bulletin, vol. 75, no. 8, pp. 3473-3498, 2018.

[16] X. Yan, X. Qian, R. Lu, and T. Miyakoshi, "Synergistic effect of addition of fillers on properties of interior waterborne UVcuring wood coatings," Coatings, vol. 8, no. 1, p. 9, 2018.

[17] J. S. Baek, J. K. Tee, Y. Y. Pang et al., "Improved bioavailability of levodopa using floatable spray-coated microcapsules for the management of Parkinson's disease," NeuroMolecular Medicine, vol. 20, no. 2, pp. 262-270, 2018.

[18] A. Mooranian, R. Negrulj, R. Takechi, J. Mamo, H. Al-Sallami, and H. Al-Salami, "The biological effects of the hypolipidaemic drug probucol microcapsules fed daily for 4 weeks, to an insulin-resistant mouse model: potential hypoglycaemic and anti-inflammatory effects," Drug Delivery and Translational Research, vol. 8, no. 3, pp. 543-551, 2018.

[19] R. Wurth, P. Foerst, and U. Kulozik, "Effects of skim milk concentrate dry matter and spray drying air temperature on formation of capsules with varying particle size and the survival microbial cultures in a microcapsule matrix," Drying Technology, vol. 36, no. 1, pp. 93-99, 2018.

[20] J. G. Wang, X. Li, M. Chen et al., "Fabrication of sustainedrelease and antibacterial citronella oil-loaded composite microcapsules based on Pickering emulsion templates," Journal of Applied Polymer Science, vol. 135, no. 25, p. 46386, 2018.

[21] Y. K. Song, B. Kim, T. H. Lee et al., "Monitoring fluorescence colors to separately identify cracks and healed cracks in microcapsule-containing self-healing coating," Sensors and Actuators B: Chemical, vol. 257, pp. 1001-1008, 2018.

[22] F. Safaei, S. N. Khorasani, H. Rahnama, R. E. Neisiany, and M. S. Koochaki, "Single microcapsules containing epoxy healing agent used for development in the fabrication of cost efficient self-healing epoxy coating," Progress in Organic Coating, vol. 114, pp. 40-46, 2018.

[23] S. Sharma and V. Choudhary, "Parametric study for epoxy loaded PMMA microcapsules using Taguchi and ANOVA methods," Express Polymer Letters, vol. 11, no. 12, pp. 10231036, 2017. 


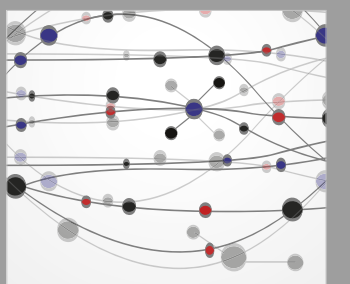

The Scientific World Journal
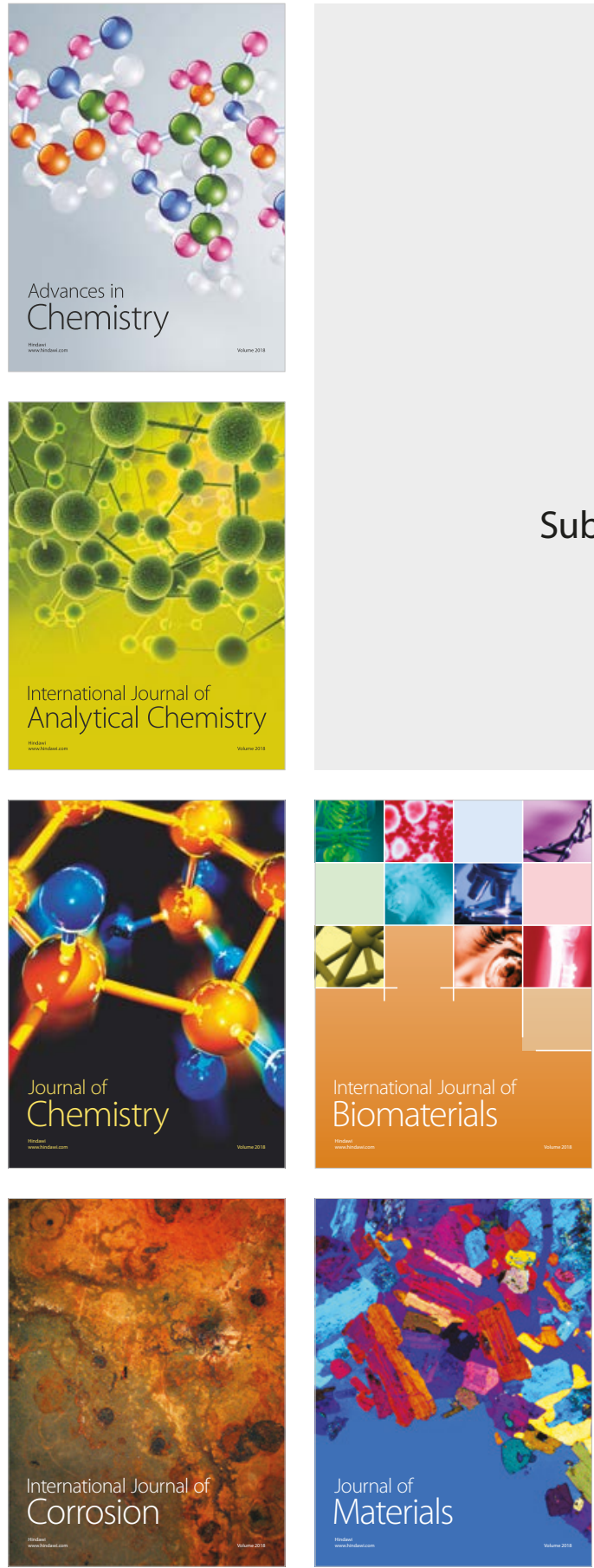

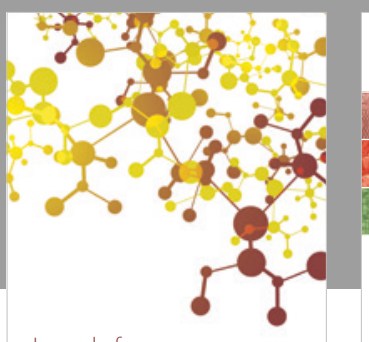

Journal of

Applied Chemistry
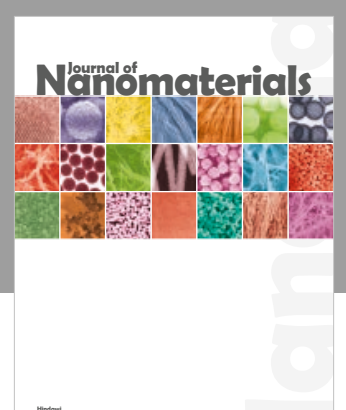

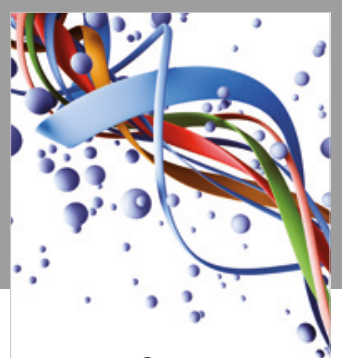

Scientifica

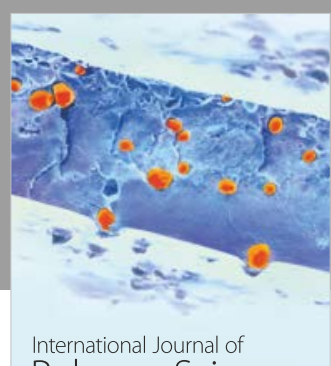

Polymer Science

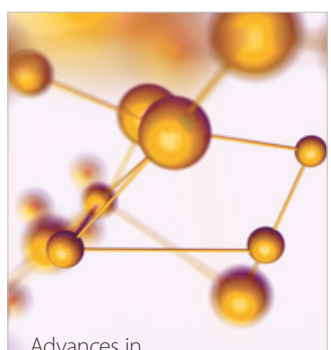

Physical Chemistry
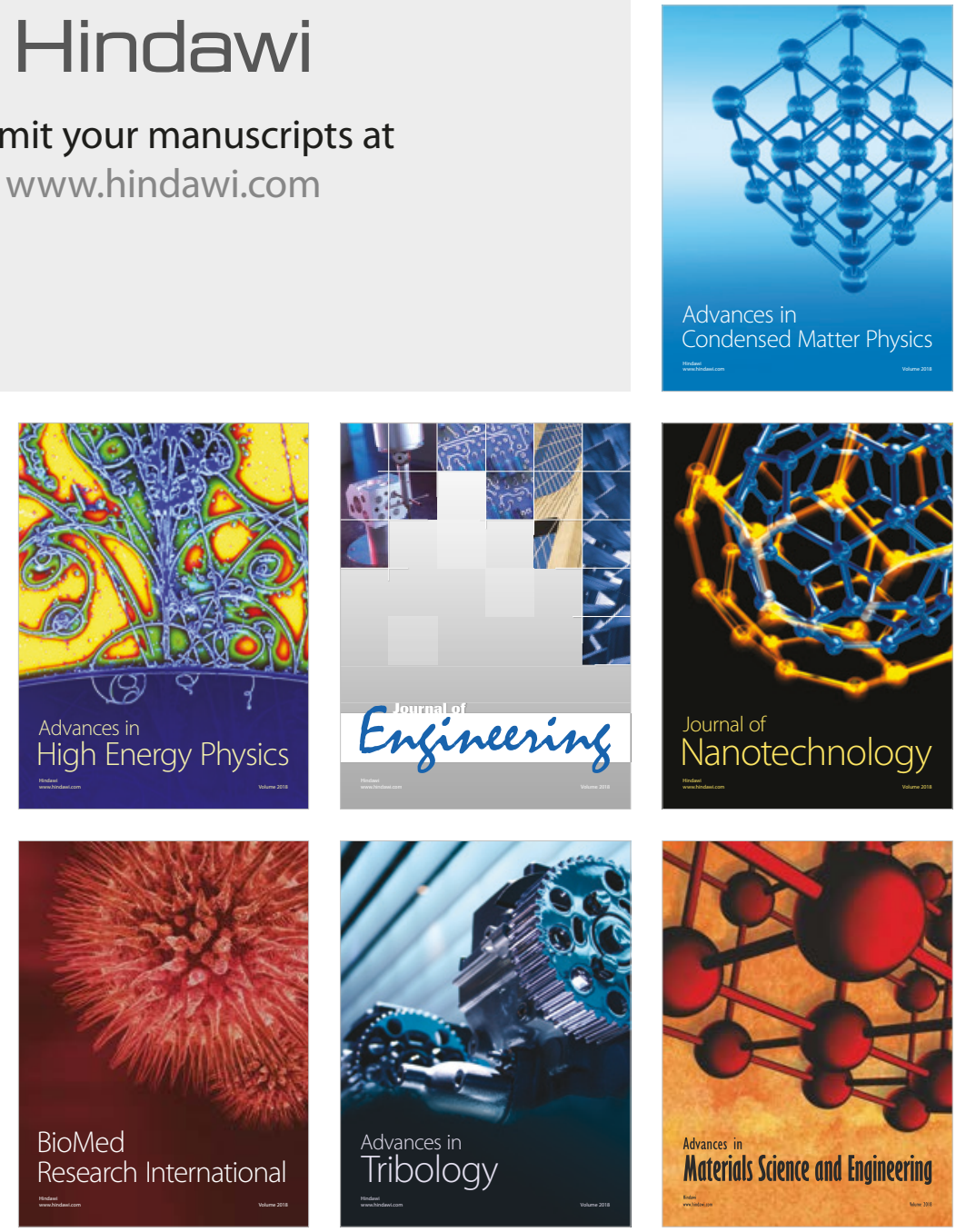